\title{
Inappropriate prescribing to older patients admitted to hospital: a comparison of different tools of misprescribing and underprescribing.
}

Antonio San-José, MD, ${ }^{1,9}$ Antonia Agustí, MD, ${ }^{2}$ Xavier Vidal, MD, ${ }^{2}$ Francesc Formiga, MD, ${ }^{3,9}$ Alfonso López-Soto, MD, 4,9 Antonio Fernández-Moyano, MD, ${ }^{5,9}$ Juana García, MD, ${ }^{6,9}$ Nieves Ramírez-Duque, MD, ${ }^{7,9}$ Olga H. Torres, MD, ${ }^{8,9}$ José Barbé, MD, ${ }^{1,9}$ on behalf of Potentially Inappropriate Prescription in Older Patients in Spain (PIPOPS) Investigators' project.

${ }^{1}$ Internal Medicine Service, Hospital Universitari Vall d'Hebron. Universitat Autònoma de Barcelona. Barcelona.

${ }^{2}$ Clinical Pharmacology Service. Fundació Institut Català de Farmacologia, Hospital Universitari Vall D'Hebron, Departament of Pharmacology, Therapeutics and Toxicology, Universitat Autònoma de Barcelona.

${ }^{3}$ Internal Medicine Service, Hospital Universitari de Bellvitge. Hospitalet de Llobregat. Barcelona.

${ }^{4}$ Internal Medicine Service. Hospital Clínic. Barcelona.

${ }^{5}$ Internal Medicine Service, Hospital San Juan De Dios del Aljarafe. Sevilla.

${ }^{6}$ Internal Medicina Service. Hospital General Juan Ramón Jiménez. Huelva.

${ }^{7}$ Internal Medicine Service. Hospital Universitario Virgen del Rocío. Sevilla.

${ }^{8}$ Internal Medicine Service. Hospital Santa Creu i Sant Pau. Universitat Autònoma de Barcelona. Barcelona.

${ }^{9}$ Multimorbidity and elderly patients group of the Spanish Society of Internal Medicine.

Corresponding Author: Antonio San-José, Internal Medicine Service, Hospital Universitari Vall d'Hebron, Àrea General $3^{\mathrm{a}}$ planta, Passeig Vall d'Hebron 119-129, 08035 Barcelona. Tel 34-932746882, Fax 34934894109

asanjose@vhebron.net 


\begin{abstract}
Purpose: This study aims to assess inappropriate prescribing (IP) to elderly patients during the month prior to hospitalization and to compare different IP criteria.

Methods: An observational, prospective and multicentric study was carried out in the internal medicine services of seven Spanish hospitals. Patients aged 75 years and older were randomly selected after hospital admission for a year. To assess potentially inappropriate medicines (PIMs), the Beers and STOPP criteria were used and to assess Potentially Prescribing Omissions (PPOs), the START criteria and ACOVE-3 medicine quality indicators were used. An analysis to assess factors associated with IP was performed.
\end{abstract}

Results: 672 patients [median age (Q1_Q3) 82 (79-86) years, 55.9\% female] were included. Median prescribed medicines in the month prior to hospitalization were 10(Q1-Q3 7-13). The prevalence of IP was 87.6\%, and $54.3 \%$ of patients had PIMs and PPOs concurrently. A higher prevalence rate of PIMs was predicted using the STOPP criteria than with the Beers criteria $(\mathrm{p}<.001)$ and a higher prevalence of PPOs using the ACOVE-3 criteria than using the START criteria $(\mathrm{p}<.001)$ was observed. Polypharmacy $(\geq 10$ medicines $)$ was the strongest predictor of IP [OR=11.34 95\% confidence interval (CI) 4.96-25.94], PIMs [OR=14.16, 95\% CI 6.44-31.12], Beers-listed PIMs [OR=8.19, 95\% CI 3.01-22.28] and STOPP-listed PIMs [OR=8.21, 95\% CI 3.47-19.44]. PIMs was the strongest predictor of PPOs [OR=2.79, 95\% CI 1.81-4.28].

Conclusions: A high prevalence of polypharmacy and PIMs and PPOs were reported. More than half the patients had simultaneous PIMs and PPOs. The related factors to PIMs and PPOs were different.

Keywords: polypharmacy, older multimorbidity patients, inappropriate prescribing, potentially inappropriate medicines, potentially

prescribing omissions. 


\section{Introduction}

Inappropriate prescribing (IP) to older people can be defined as a situation in which pharmacotherapy is not within accepted medical standards. This can include overprescribing, misprescribing, and underprescribing [1-5].

Different criteria have been developed to identify the appropriate use of medicines in people $\geq 65$ years old. Some are based on clinical judgements (implicit criteria) and others, the most widespread, on predetermined standards (explicit criteria). The explicit criteria include Potentially Inappropriate Medicines (PIMs) that should be avoided in any circumstances and drugs that should be avoided in patients with specific disorders [1, 6-8]. The most widely disseminated are the Beers [9, 10] and the STOPP (Screening Tool of Older Person's Prescriptions) criteria [11]. The prevalence of PIMs described in the studies range from $25 \%$ to $75 \%$ of patients and polypharmacy is the main factor associated with PIMs [12-14].

The criteria for IP of medicines in older people focusing on the detection of underprescribing or Potentially Prescribing Omissions (PPOs) are more recent. The START (Screening Tool to Alert doctors to Right Treatment) criteria are a new tool in screening for PPOs in the elderly population, and the published results indicate a very high prevalence, between 51 and $72 \%$ of patients $[13,15]$.

Also for the most vulnerable older people, some health care quality indicators (Assessing Care of Vulnerable Elders - ACOVE) have been identified in recent years. The ACOVE project approach is more comprehensive as it includes pharmacologic care indicators [16, 17]. Studies in the United States, focusing on the ACOVE pharmacologic care indicators, show that underprescribing indicators get the worst results, affecting $50 \%$ of patients [18].

The objectives of the study were to analyze medicine consumption and inappropriate use of medications the month prior to hospital admission in medical units in older patients; to compare different tools of inappropriate prescribing focusing on PIMs (STOPP and Beers criteria) and PPOs (START criteria and ACOVE underprescribing indicators), and to explore factors associated with inappropriate use of medicines. 


\section{Methods}

An observational, prospective, multicentric study of a cohort of patients hospitalised in the Internal Medicine Services of seven Spanish hospitals was carried out for a year (from April 2011 to March 2012).

Patients, 75 years or older, admitted with an acute illness or an exacerbation of a chronic condition who signed the informed consent, were included. Hospital admission was through either the emergency department or directly from primary care. Patients with a scheduled or a short-duration (less than 24 hours) admission, those seen as an outpatient by the researcher, and those where no access was available to primary care medical information, were excluded from the study.

Information on a patient's variables was obtained from the hospital and the primary care electronic medical records and from interviews with the patients and/or relatives, using a structured questionnaire. On admission, data about patient's age, gender, and social characteristics such as residence (home, nursing home or another hospital) and living conditions (single, with a partner or relative or other), and frequency of health care services utilization (number of visits to general practitioner or hospital admissions) for one month prior to admission, was collected.

In addition, information on activities of daily living, basal (one month previous to admission) and on admission (during the first 48 hours), using the Barthel index [19], cognitive function using the Pffeifer scale [20] and the Global Deterioration Scale (GDS) [21], specific diagnosis and cumulative multimorbitity as quantified by the Charlson Co-morbidity index [22] and the polypathological patient scale [23], number of falls in the preceding 3 months and delirium during the first 48 hours of admission using the Confusion Assessment Method [CAM] [24], was assessed. On discharge, data about fate on discharge (home, nursing home, or another hospital) and the Barthel index score were obtained.

Regarding medicine exposure, information on the number, type, dosage and duration of prescription medicines in the preceding month before admission was obtained using a complete pharmacological anamnesis. This consisted of an open question asking patients or their relatives, in the case of cognitively impaired patients, about medicine exposure for one month before admission, followed by several questions about medicine exposure for common symptoms and conditions frequently treated with medicines. Information from the primary care electronic medical record was used to complete the data. In case of conflict regarding medication information, patient or caregiver data was considered to be the main information. Medicines were classified according to the Anatomical Therapeutic classification system (ATC).

Beers [9], STOPP and START criteria [11, 15, 25] and ACOVE-3 underprescribing indicators for chronic conditions were applied to each dataset on admission. The ACOVE 3 contains a total of 26 chronic conditions and 392 quality indicators [16, 17]. Of these, 142 quality indicators pertained to pharmacologic care. Following the methodology used in other studies [18], the pharmacologic indicators were stratified into 4 domains: "prescribing indicated medications" with 68 indicators, "avoiding inappropriate medications" with 19 indicators, 
"education, continuity, and documentation" with 43 indicators and "monitoring" with 12 indicators. Finally, 11 out of the total 26 conditions, and their corresponding 37 quality indicators from the prescribing indicated medications domain were selected for the study (see Appendix 2 on the online material only). To choose these eleven chronic conditions from ACOVE 3, the prevalence of the conditions in the elderly, the number of the quality pharmacologic indicators of the condition and finally, the similitude with other underprescribing tools such as the START criteria were taken into account. Four researchers (a geriatrician, a medical internist and two clinical pharmacologists with experience in geriatric assessment and prescribing medicines to elderly patients) independently selected the ACOVE 3 chronic conditions and the underprescribing indicators for the study. Differences were resolved by consensus [26]. A good level of inter-rater reliability has been described for the Beers, the STOPP/START criteria and the underprescribing ACOVE indicators [13, 26, 27]. All the interviewers were consultants or nurses trained in geriatric assessment and in the use of inappropriate prescribing criteria.

In the study, global IP was considered when at least one Beer's, STOPP, START and/or ACOVE criteria was present. Global PIM was considered when at least one Beers and/or STOPP criteria was prescribed, and global PPO, when at least one START and/or ACOVE-3 criteria was omitted, Beers-listed PIM, when at least one of the Beers criteria was prescribed, STOPP-listed PIM, when at least one STOPP criteria was prescribed, STARTlisted PPO, when at least one START criteria was omitted, and ACOVE3-listed PPO, when at least one ACOVE3 criteria was omitted.

The study was conducted according to international ethical recommendations in accordance with the national directives in relation to post-authorization studies. The study was approved by the Ethics Committee of Clinical Investigation in each participating hospital.

\section{Sample size and sampling method}

A sample of around 400 patients must be included to estimate $50 \%$ of inappropriate prescribing with a precision of $\pm 5 \%$ (95\% confidence limits). To obtain enough information on the different age groups, around 700 patients had to be included, 350 of whom were $\geq 75$ to 84 years old and $350 \geq 85$ years old. To fit the calculated sample size, each hospital included 2 patients per week (one in each age group) admitted with the inclusion criteria. Patients were selected randomly every week on consecutive days from the hospitalization lists.

\section{Statistical analysis}

Since the study design oversampled the proportion of older patients, and the number of eligible patients was different for the participating centres, analyses were weighted by age distribution and frequency of the eligible population in each hospital. To examine the association between inappropriate prescribing and potential risk factors, a multivariate logistic regression analysis was performed where an inappropriate prescribing indicator was the dependent variable and sociodemographic variables, multimorbidity ( $\geq 2$ clinical categories of the Polypathological Patient scale)[23] and geriatric conditions, and number of prescription medicines in the 
preceding month before hospitalization were the independent variables. The adjusted Odds ratio (OR) with its 95\% confidence intervals (CI) was calculated. Significance was set at a level of 0.05 , and was two-tailed. Statistical analysis was performed using the procedures for complex surveys of the SAS 9.2 program (SAS Institute Inc., Cary, $\mathrm{NC}$, USA). 


\section{Results}

A total of six hundred and seventy-two patients were included in the study, with a median (Q1-Q3) age of 82 (79-86) years, and 55.9\% were female. Table 1 shows the main baseline characteristics of the study population. The most frequent chronic conditions were arterial hypertension (78.3\% of patients), heart failure (42.8\%), chronic obstructive pulmonary disease (31\%), diabetes mellitus (30.9\%), cerebrovascular disease $(27.2 \%)$ and dementia (18.4\%). Sixty percent of patients were independent or slightly dependent for activities of daily living according to the Barthel index. The baseline cognitive function was normal (Reisberg of 1 or 2 ) in $57.4 \%$ of patients and $52.7 \%$ out of 565 had a normal cognitive performance on admission according to the Pfeiffer test.

Median prescribed medicines during the month prior to admission was 10 (Q1-Q3 7-13) per patient; between 0 and 4 medicines were prescribed to $7.6 \%$ of patients, between 5 and 9 to $36.5 \%$ and ten or more to $55.9 \%$. Omeprazole (61.1\% of patients), acetaminophen $(47.3 \%)$ and furosemide $(45.2 \%)$ were the most frequently prescribed medicines and by subgroups the most frequently prescribed were agents for acid related disorders (76.8\%), followed by antithrombotic agents $(67.1 \%)$ and diuretics $(66.2 \%)$.

Distribution of patients into the groups of IP is shown in figure 1. The global IP prevalence rate was $87.6 \%$ and most patients $(54.3 \%)$ had concurrent global PIMs and global PPOs. Using the STOPP criteria, the PIMs prevalence rate was higher (61.3\%) than using the Beer's criteria (51.1\%) (Difference $=10.3 \%$, 95\% CI 5.7\%$14.8 \%, \mathrm{p}<.001$ ), and using the ACOVE criteria, the PPO prevalence rate was also higher (56.5\%) than using the START criteria $(51.3 \%)($ Difference $=5.2 \%, 95 \%$ CI, $1.3 \%-9.1 \%, \mathrm{p}<.001)$.

The most frequently found PIMs according to the Beers' criteria was the use of long-acting benzodiazepines (11.8\%) independent of diagnoses or conditions, and the prescription of short to intermediate-acting benzodiazepines and tricyclic antidepressants to patients with previous falls or syncope (9.9\%). The most commonly encountered STOPP criteria included use of benzodiazepines to patients who are prone to falls (15.0\%) and the use of long-term long-acting benzodiazepines (11.5\%). Among the START criteria the most frequently identified PPOs were ACE inhibitors to patients with heart failure (15.0\%) and oral anticoagulation in the presence of chronic atrial fibrillation (11.5\%). The most commonly identified PPOs by the ACOVE criteria were ACE inhibitors or angiotensin-receptor blockers to patients with hypertension and comorbid vascular diseases (10.8\%), and oral anticoagulation to patients with chronic atrial fibrillation who are at medium to high risk of stroke $(9.0 \%)$ (Table 2).

Prescription of ten or more medicines was the strongest independent risk factor associated with global IP and global PIM (OR= 11.34, 95\% CI, 4.96-25.94 and $\mathrm{OR}=14.16,95 \% \mathrm{CI}, 6.44-31.12$, respectively) (Table 3). Global PIM (OR= 2.79, 95\% CI, 1.81-4.28) was the strongest independent predictor of global PPO (Table 3).

When independent risk factors associated with the different criteria of IP were analysed a prescription of ten or more medicines was the strongest predictor of PIM according to the Beer's and the STOPP criteria (OR= 8.19, 95\% CI, 3.01-22.28 and OR= 8.21, 95\% CI, 3.47-19.44, respectively) (Table 4). The strongest independent 
predictors of PPO according to the START criteria were non-community dwelling (OR=1.82, 95\% CI, 1.02 3.24) and multimorbidity ( $\mathrm{OR}=1.76,95 \% \mathrm{CI}, 1.14-2.7)$, and identification of at least one STOPP-listed criteria was the independent risk factor of PPO according to the ACOVE 3 (OR=2.3, 95\% CI, 1.51-3.49) (Table 4). 


\section{Discussion}

This study focused on a comprehensive assessment of IP in older patients using different tools of PIMs as well as PPOs. In our study the prevalence of polypharmacy and the prevalence of PIMs and PPOs were high and a large proportion of patients had PIMs and PPOs concurrently according to the used instruments. In addition, a higher prevalence rate of PIMs was predicted using the STOPP criteria than with the Beers criteria and a higher prevalence of PPOs using the ACOVE-3 criteria than using the START criteria was observed.

The study population was a group of very elderly patients who were mostly admitted through the emergency department with an acute illness or an exacerbation of a chronic condition and most of them came from home. They had a significant multimorbidity, mild dependence for basic activities of daily living and a good baseline cognitive performance. Most of them were discharged and went home. In our study, polypharmacy was higher than that described in other studies focusing on patients' medicine consumption on hospital admission [11, 13, 28]. However, an exhaustive pharmacology anamnesis study was carried out in our study analysing the consumption of drugs the month before admission, not only at the time of admission, as well as a complete review of drug utilization from the primary care and hospital electronic medical records, and performing an exhaustive drug interview of patients and/or relatives. This can explain, at least in part, the differences in comparison with other studies.

Almost ninety percent of patients were prescribed at least one global IP criteria. Our results also showed that more than half of our study population had simultaneous global PIM and global PPO criteria. Finally, when PIM or PPO was independently analyzed using the different listed criteria, a very high rate of PIM and PPO was encountered in each one. These rates are slightly higher than those described in a recent European multicentric study [13].This comprehensive analysis of global IP has allowed us to show the complexity of medicines prescribed to the elderly. As in most of our study population, polypharmacy and prescription of global PIM and global PPO concurred. A study showed that more than $40 \%$ of patients with polypharmacy had both PIM and PPO and that the risk factors associated with PIM differed to those associated with PPO [5].

In other series, the use of benzodiazepines has also been the most common described PIM, although with lower percentages [11, 13]. In another recent study, the use of proton pump inhibitors was the most frequently described PIM according to the STOPP criteria [14]. Regarding the PPO, our results are similar to those reported in other studies albeit the omission rate of ACE inhibitors or angiotensin receptor blockers and of oral anticoagulants was higher in our study and it was lower than that of calcium or vitamin D and of statins [13].

In our study, polypharmacy was the strongest independent predictor of global IP, global PIM, Beer's-listed PIM and STOPP-listed PIM criteria. Other strong predictors were female gender for global IP, global PIM and Beer's-listed PIM criteria and, total dependence on basal activities of daily living for only global PIM and STOPP-listed PIM criteria. Polypharmacy and female gender have been described as PIM prescription predictors 
in other studies $[5,11,13,29]$ as well as other factors such as a history of falls that have not appeared in our study [29]. The association between total dependence on activities of daily living and PIM prescription is a novel finding requiring evaluation in further studies. A recent study showed a high prevalence of PIM prescription according to the STOPP criteria in nursing homes, and one third of these prescribed medicines were central nervous system acting drugs [30]. The inverse association between multimorbidity and STOPP-listed PIM is noteworthy, but a plausible interpretation is that multimorbidity might be associated with a more appropriate polypharmacy.

In our study, the strongest independent predictor of global PPO was global PIM. This association and that of ACOVE3- listed PPO with STOPP-listed PIM may be due to the fact that most patients in the study had simultaneous potentially inappropriate medicines and potentially prescribing omissions. This is an interesting data that need to be confirmed in further studies. Independent predictors of START-listed PPO criteria were multimorbidity and an origin other than home. PPO predictors described in other studies according to the START criteria have been aged over 85 years [13, 15], female gender [15], and multimorbidity [13].

In the present study, the ACOVE-3 criteria were a good screening PPO instrument, and a higher PPO prevalence was encountered in comparison to the START criteria. Our results should lead to these criteria being used as a screening instrument for PPO. The high percentages of underprescribing of medicines reported in our study and others should be viewed with caution in as much as these criteria have been developed by expert groups based on their experience and scientific evidence. The lack of high quality evidence in the treatment of major chronic diseases in elderly patients with multimorbidity is well known [29,31,32].

This study has some limitations. Firstly, there is no previous experience in the use of the ACOVE medication quality indicators on the detection of PPO. However, given the lack of criteria for underprescribing in the elderly, and the comprehensive pharmacological approach of the ACOVE project, especially focusing on underprescribing, we considered it of interest to select these quality indicators and make the comparison with the START underprescribing criteria. Secondly, a previous version of the Beers criteria, which was the latest currently available, has been used in our study, and our results should be confirmed by using the most recently published version [10].

In conclusion, with the comprehensive analysis of IP in older people done in our study using different instruments on hospital admission a high prevalence of polypharmacy and a high prevalence of PIMs and PPOs were reported. In most of our population both PIMs and PPOs were simultaneously identified. The kind of PIMs and PPOs and even the associated factors were similar to those reported in other studies. More studies focusing on inappropriate prescription instruments in older people and especially in multimorbidity older people, are needed. 


\section{Conclusions or key points:}

- More than half of our study population had simultaneous potentially inappropriate medicines and potentially prescribing omissions.

- A higher prevalence rate of PIMs was predicted using the STOPP criteria than with the Beers criteria and a higher prevalence of PPOs using the ACOVE-3 criteria than using the START criteria was observed.The risk factors associated to potentially inappropriate medicines differed to those associated with potentially prescribing omissions.

- Pharmacologic care indicators focused on prescribing indicated medications of the ACOVE 3 can be considered a useful tool in detecting underprescribing in the elderly.

\section{Learning points:}

- Polypharmacy among older people is prevalent and it is associated with a high prevalence of potentially inappropriate medicines.

- More studies are needed to better know the factors associated with potentially prescribing omissions.

- A high proportion of older people may simultaneously have potentially inappropriate medicines and potentially prescribing omissions.

- Prescribing indicated medications of the ACOVE 3 can be considered a useful tool in detecting underprescribing in the elderly. 


\section{PIPOPS investigators}

Coordinator group: Antonio San-José (main investigator), Antònia Agustí, Xavier Vidal, Cristina Aguilera, Elena Ballarín, Eulàlia Pérez, Xavier Barroso

Hospital Universitari Vall D’hebron (Barcelona): José Barbé, Carmen Pérez Bocanegra, Ainhoa Toscano, Carme Pal, Teresa Teixidor

Hospital San Juan de Dios de Aljarafe (Sevilla): Antonio Fernández-Moyano, Mercedes Gómez Hernández, Rafael de la Rosa Morales, María Nicolás Benticuaga Martínez

Hospital Clínic (Barcelona): Alfonso López-Soto, Xavier Bosch, Mª José Palau, Joana Rovira, Margarita Navarro

Hospital Universitari de Bellvitge (Hospitalet de Llobregat, Barcelona): Francesc Formiga, David Chivite,

Beatriz Rosón, Antonio Vallano, Carme Cabot

Hospital Juan Ramón Jiménez (Huelva): Juana García, Isabel Ballesteros

Hospital Santa Creu i Sant Pau (Barcelona): Olga H. Torres, Domingo Ruiz, Miquel Turbau, Paola Ponte,

Gabriel Ortiz

Hospital Universitario Virgen Del Rocío (Sevilla): Nieves Ramírez-Duque, Paula-Carlota Rivas Cobas, Paloma Gil

\section{Conflict of interest}

The authors declare that they have no conflict of interest.

\section{Acknowledgments}

The project was financed by Grant no. EC10-211 obtained in a request for aid for the promotion of independent clinical research (SAS/2370/2010 Order of 27 September from the Spanish Ministry of Health, Social Affairs and Equality). 
Author contributions: San-Jose A., and Agustí A., as directors and project leaders had devised and wrote the proposal for obtaining the grant, wrote the manuscript and had final responsibility for the decision to submit the manuscript for publication. San-Jose A., Agustí A., Vidal X., Formiga F., López-Soto A., Fernández-Moyano A., García J., Ramírez-Duque N., Torres O.H., Barbé J., contributed to the study design, coordinated data collection in each hospital, interpreted the data, reviewed the manuscript, provided comments and approved the final text of the manuscript. Vidal X., conducted statistical analysis. Ballarín E., and Pérez E., controlled and monitorized quality data. Barroso X., designed the database. Aguilera A., Pérez C., Toscano A., Pal C., Teixidor T., Chivite D,. Rosón B., Vallano A., Cabot C., Ballesteros I., Ruiz D., Turbau M., Ponte P., Ortiz G., Rivas Cobas PC., Gil P., Gómez Hernández M., De la Rosa Morales R., Benticuaga Martínez MN., Bosch X, Palau MaJ., Rovira J., Navarro M., collected the data. 


\section{References}

[1] Spinewine A, Schmader KE, Barber N, Hughes C, Lapane KL, Swine C, Hanlon JT . Appropriate prescribing in elderly people: how well can it be measured and optimised? Lancet 2007;370:173-84.

[2] O’Mahony D, Gallagher PF. Inappropriate prescribing in the older population: need for new criteria. Age Ageing 2008;37:138-41.

[3] Roth MT, Weinberger M, Campbell WH. Measuring the quality of medication use in older adults. J Am Geriatr Soc 2009;57:1096-102.

[4] Cho S, Lau SW, Tandon V, Kumi K, Pfuma E, Abernethy DR. Geriatric drug evaluation: where are we now and where should we be in the future? Arch Intern Med 2011;171:937-40.

[5] Steinman MA, Landefeld CS, Rosenthal GE, Berthenthal D, Sen S, Kaboli PJ. Polypharmacy and prescribing quality in older people. J Am Geriatr Soc 2006;54:1516-23.

[6] Chang CB, Chan DC. Comparison of published explicit criteria for potentially inappropriate medications in older adults. Drugs Aging 2010;27:947-57.

[7] Chang CB, Chen JH, Wen CJ, Kuo HK, Lu IS, Chiu LS, Wu SC, Chan DC. Potentially inappropriate medications in geriatric outpatients with polypharmacy: application of six sets of published explicit criteria. $\mathrm{Br} \mathbf{J}$ Clin Pharmacol 2011;72:482-9.

[8] Dimitrow MS, Airaksinen MS, Kivelä SL, Lyles A, Leikola SN. Comparison of prescribing criteria to evaluate the appropriateness of drug treatment in individuals aged 65 and older: a systematic review. J Am Geriatr Soc 2011;59:1521-30.

[9] Fick DM, Cooper JW, Wade WE, Waller JL, Maclean JR, Beers MH. Updating the Beers criteria for potentially inappropriate medication use in older adults: results of a US consensus panel of experts. Arch Intern Med 2003;163:2716-24.

[10] American Geriatrics Society 2012 Beers Criteria Update expert panel. American Geriatics Society updated Beers Criteria for potentially inappropriate medication use in older adults. J Am Geriatr Soc 2012;60:616-31.

[11] Gallagher PF, O’Mahony D. STOPP (screening tool of older persons' potentially inappropriate prescriptions): application to acutely ill elderly patients and comparison with Beers' criteria. Age Ageing 2008; 37: 673-9.

[12] Fialová D, Topinková E, Gambassi G, Finne-Soveri H, Jónsson PV, Carpenter I, Schroll M, Onder G, Sørbye LW, Wagner C, Reissigová J, Bernabei R; AdHOC Project Research Group. Potentially inappropriate medication use among elderly home care patients in Europe. JAMA 2005;293:1348-58.

[13] Gallagher P, Lang PO, Cherubini A, Topinková E, Cruz-Jentoft A, Montero Errasquín B, Mádlová P, Gasperini B, Baeyens H, Baeyens JP, Michel JP, O'Mahony D. Prevalence of potentially inappropriate prescribing in an acutely ill population of older patients admitted to six European hospitals. Eur J Clin Pharmacol 2011;67:1175-88.

[14] Hamilton H, Gallagher P, Ryan C, Byrne S, O'Mahony D. Potentially inappropriate medications defined by STOPP criteria and the risk of adverse drug events in older hospitalized patients. Arch Intern Med 2011;171: $1013-9$. 
[15] Barry PJ, Gallagher P, Ryan C, O'mahony D. START (screening tool to alert doctors to the right treatment)-an evidence-based screening tool to detect prescribing omissions in elderly patients. Age Ageing 2007;36:6328.

[16] Wenger NS, Roth CP, Shekelle P, and the ACOVE investigators. Introduction to the assessing care of vulnerable elders 3 quality indicators measurement set. J Am Geriatr Soc 2007;55(Suppl 2):S247-S52.

[17] Assessing care of vulnerable elders-3 quality indicators. J Am Geriatr Soc 2007;55 (Suppl 2): S464-S87.

[18] Higashi T, Shekelle PG, Solomon DH, Knight EL, Roth C, Chang JT, Kamberg CJ, MacLean CH, Young

RT, Adams J, Reuben DB, Avorn J, Wenger NS. The quality of pharmacologic care for vulnerable older patients. Ann Intern Med 2004;140:714-20.

[19] Mahoney FI, Barthel DW. Functional evaluation: The Barthel index. A simple index of independence useful in scoring improvement in the rehabilitation of the chronically ill. Md State Med J 1965;14:61-5.

[20] Pfeiffer E. A short portable mental status questionnaire for the assessment of organic brain deficit in elderly patients. J Am Geriatr Soc 1975;23:433-41.

[21] Auer S, Reisberg B. The GDS/FAST staging system. Int Psychogeriatr 1997;9 Suppl 1: 167-71.

[22] Charlson ME, Pompei P, Ales KL, Mackenzie CR. A new method of classifying prognostic comorbidity in longitudinal studies: development and validation. J Chronic Dis 1987;40:373-83.

[23] Bernabeu-Wittel M, Ollero-Baturone M, Moreno-Gaviño L, Barón-Franco B, Fuertes A, Murcia-Zaragoza

J, Ramos-Cantos C, Alemán A, Fernández-Moyano A. Development of a new predictive model for polypathological patients. The Profund index. Eur J Intern Med 2011;22:311-7.

[24] Inouye SK, Van Dyck CH, Alessi CA, Balkin S, Siegal AP, Horwitz RI. Clarifying confusion : the confusion assessment method. A new method for detection of delirium Ann Intern Med 1990;113:941-8.

[25] Delgado Silveira E, Muñoz García M, Montero Errasquin B, Sánchez Castellano C, Gallagher PF, CruzJentoft AJ. [Inappropriate prescription in older patients: the STOPP/START criteria]. Rev Esp Geriatr Gerontol 2009;44: 273-9. (Article in Spanish)

[26] San-José A, Agustí A, Vidal X, Barbé J, Torres OH, Ramírez-Duque N, García J, Fernández-Moyano A, López-Soto A, Formiga F; on behalf of Potentially Inappropriate Prescribing in Older Patients in Spain (PIPOPS) Investigators' Project. An inter-rater reliability study of the prescribing indicated medications quality indicators of the Assessing Care Of Vulnerable Elders (ACOVE) 3 criteria as a potentially inappropriate prescribing tool. Arch Gerontol Geriatr 2014;58: 460-4.

[27] Gallagher P, Baeyens JP, Topinkova E, Madlova P, Cherubini A, Gasperini B, Cruz-Jentoft A, Montero B, Lang PO, Michel JP, O'Mahony D. Inter-rater reliability of STOPP (Screening Tool of Older Persons' Prescriptions) and START (Screening Tool to Alert doctors to Right Treatment) criteria amongst physicians in six European countries. Age Ageing 2009;38:603-6.

[28] Dalleur O, Spinewine A, Henrard S, Losseau C, Speybroeck N, Boland B. Inappropriate prescribing and related hospital admissions in frail older persons according to the STOPP and START criteria. Drugs Aging. 2012;29:829-37.

[29] Boyd CM, Darer J, Boult C, Fried LP, Boult L, Wu AW. Clinical practice guidelines and quality of care for older patients with multiple comorbid diseases: implications for pay for performance. JAMA 2005;294:716-24. [30] Ryan C, O’Mahony D, Kennedy J, Weedle P, Cottrell E, Heffernan M, O'Mahony B, Byrne S. Potentially inappropriate prescribing in older residents in Irish nursing homes. Age Ageing 2013;42:116-20. 
[31] Hughes LLD, McMurdo MET, Guthrie B. Guidelines for people not for disease: the challenges of applying UK clinical guidelines to people with multimorbisity. Age Ageing 2013;42:62-9.

[32] American Geriatrics Society expert panel on the care of older adults with multimorbidity. Guiding principles for the care of older adults with multimorbidity: an approach for clinicians. J Am Geriatr Soc 2012;60:E1-E25. 
Table 1 Baseline characteristics of patients (weighted percentages).

\begin{tabular}{|c|c|}
\hline Baseline characteristics & Patients $(n=672)$ \\
\hline $\begin{array}{l}\text { Age }(\text { Median }[Q 1-Q 3]) \\
\text { Age }(\%) \\
75-84 \text { years } \\
85 \text { and more } \%\end{array}$ & $\begin{array}{c}82(79-86) \\
63.9 \\
36.1 \\
\end{array}$ \\
\hline $\begin{array}{l}\text { Gender }(\%) \\
\text { Female } \\
\text { Male }\end{array}$ & $\begin{array}{l}55.9 \\
44.1 \\
\end{array}$ \\
\hline $\begin{array}{l}\text { Reason for admission }(\%) \\
\text { Acute disease } \\
\text { Exacerbation of a chronic disease }\end{array}$ & $\begin{array}{l}51.4 \\
48.6 \\
\end{array}$ \\
\hline $\begin{array}{l}\text { Origin }(\%) \\
\text { Emergency room } \\
\text { Others }\end{array}$ & $\begin{array}{c}93.3 \\
6.7 \\
\end{array}$ \\
\hline $\begin{array}{l}\text { Dwelling }(\%) \\
\text { Community } \\
\text { Nursing Home } \\
\text { Others }\end{array}$ & $\begin{array}{c}87.1 \\
11.5 \\
1.4 \\
\end{array}$ \\
\hline $\begin{array}{l}\text { Living with }(\%) \\
\text { Couple/Family } \\
\text { Single } \\
\text { Others }\end{array}$ & $\begin{array}{l}69.5 \\
14.5 \\
16.0\end{array}$ \\
\hline $\begin{array}{l}\text { General Practitioner visits during the previous month }(\%) \\
\text { None } \\
\text { One or two } \\
\text { Three or more }\end{array}$ & $\begin{array}{l}40.0 \\
48.3 \\
11.7\end{array}$ \\
\hline $\begin{array}{l}\text { Admissions during the previous month }(\%) \\
\text { None } \\
\text { One } \\
\text { Two or more }\end{array}$ & $\begin{array}{c}85.2 \\
12.7 \\
2.1\end{array}$ \\
\hline $\begin{array}{l}\text { Barthel index (Median [Q1-Q3]) } \\
\text { Basal } \\
\text { On admission } \\
\text { At discharge (616 patients) }\end{array}$ & $\begin{array}{l}75(45-90) \\
40(15-65) \\
55(25-75)\end{array}$ \\
\hline $\begin{array}{l}\text { Reisberg basal }(\%) \\
1-2 \\
3-5 \\
6-7\end{array}$ & $\begin{array}{l}57.3 \\
31.0 \\
11.7\end{array}$ \\
\hline Positive CAM at admission (\%) & 14.3 \\
\hline Failures in Pfeiffer test (Median [Q1-Q3]) (565 patients) & $2(1-4)$ \\
\hline Charlson index (Median [Q1-Q3]) & $3(1-4)$ \\
\hline Multimorbidity $^{\mathrm{a}}(\%)$ & 62.0 \\
\hline $\begin{array}{l}\text { Discharged to }(\%) \\
\text { Home } \\
\text { Nursing Home } \\
\text { Died } \\
\text { Others }\end{array}$ & $\begin{array}{l}75.0 \\
16.8 \\
7.2 \\
1.0\end{array}$ \\
\hline
\end{tabular}

Q1: $1^{\text {st }}$ quartile; Q3: $3^{\text {rd }}$ quartile; CAM: Confusion Assessment Method

${ }^{\mathrm{a}}$ ( $\geq 2$ clinical categories in the Polypathological Patient scale) [23] 
Table 2. The most commonly encountered PIMs and PPO according to the respective instruments.

\begin{tabular}{|c|c|c|}
\hline \multicolumn{3}{|c|}{ Beers-listed PIM } \\
\hline Condition & Drug & $\%$ \\
\hline $\begin{array}{l}\text { Independent of diagnoses or } \\
\text { conditions }\end{array}$ & Long-acting benzodiazepines & 11.8 \\
\hline Syncope or falls & $\begin{array}{l}\text { Short-to intermediate-acting benzodiazepines and tricyclic } \\
\text { antidepressants }\end{array}$ & 9.9 \\
\hline Depression & Long-term benzodiazepine use. Sympatholytic agents & 8.1 \\
\hline $\begin{array}{l}\text { Blood clotting disorders or } \\
\text { receiving anticoagulant therapy }\end{array}$ & Aspirin, NSAIDs, dipyridamole, ticlopidine and clopidogrel & 6.6 \\
\hline Chronic constipation & $\begin{array}{l}\text { Calcium channel blockers, anticholinergics, and triclyclics } \\
\text { antidepressants }\end{array}$ & 6.4 \\
\hline \multicolumn{3}{|c|}{ STOPP-listed PIM } \\
\hline System & Drug & $\%$ \\
\hline $\begin{array}{l}\text { Drugs that adversely affect } \\
\text { those who are prone to falls }\end{array}$ & Benzodiazepines & 15.0 \\
\hline Central nervous system & Long-term, long-acting benzodiazepines & 11.5 \\
\hline Musculoeskeletal system & $\begin{array}{l}\text { Long-term NSAID for relief of mild-moderate joint pain in } \\
\text { osteoarthritis }\end{array}$ & 8.5 \\
\hline Duplicate drug classes & Any regular duplicate drug class prescription & 8.3 \\
\hline Cardiovascular system & $\begin{array}{l}\text { Aspirin with no history of coronary, cerebral or } \\
\text { peripheral arterial symptoms or occlusive arterial } \\
\text { event }\end{array}$ & 7.6 \\
\hline \multicolumn{3}{|c|}{ START-listed PPO } \\
\hline System & Drug & $\%$ \\
\hline Cardiovascular system & ACE inhibitor with chronic heart failure. & 13.4 \\
\hline Cardiovascular system & Warfarin in the presence of chronic atrial fibrillation & 11.2 \\
\hline Cardiovascular system & $\begin{array}{l}\text { Statin therapy with a documented history of coronary, } \\
\text { cerebral or peripheral vascular disease, where the } \\
\text { patient's functional status remains independent for } \\
\text { activities of daily living and life expectancy is }>5 \\
\text { years. }\end{array}$ & 8.2 \\
\hline Musculoeskeletal system & $\begin{array}{l}\text { Calcium and vitamin D supplement in patients with } \\
\text { known osteoporosis (radiological evidence or previous } \\
\text { fragility fracture or acquired dorsal kyphosis). }\end{array}$ & 7.6 \\
\hline Respiratory System & $\begin{array}{l}\text { Regular inhaled beta- } 2 \text { agonist or anticholinergic agent for } \\
\text { mild to moderate asthma or COPD. }\end{array}$ & 6.1 \\
\hline \multicolumn{3}{|c|}{ ACOVE3-listed PPO } \\
\hline Condition & Drug & $\%$ \\
\hline Hypertension (HTN) & $\begin{array}{l}\text { Angiotensin- Converting Enzyme (ACE) inhibitor for } \\
\text { comorbid vascular disease. } \\
\text { IF a VE with HTN has a history of Heart Failure (HF), left } \\
\text { ventricular hypertrophy, IHD, chronic kidney disease, or } \\
\text { cardiovascular accident, THEN he or she should be treated } \\
\text { with an ACE inhibitor or Angiotensin - receptor blockers } \\
\text { (ARB). }\end{array}$ & 10.8 \\
\hline Stroke and Atrial Fibrillation & $\begin{array}{l}\text { Anticoagulate atrial fibrillation. } \\
\text { IF a VE has chronic atrial fibrillation and is at medium to high } \\
\text { risk of stroke, THEN anticoagulation should be offered. }\end{array}$ & 9.0 \\
\hline $\begin{array}{l}\text { Chronic obstructive pulmonary } \\
\text { disease (COPD) }\end{array}$ & $\begin{array}{l}\text { Rapid-acting bronchodilator } \\
\text { IF a VE has COPD (GOLD Stage }>\text { I), THEN he or she should } \\
\text { be prescribed a rapid-acting bronchodilator. }\end{array}$ & 8.9 \\
\hline Osteoporosis & $\begin{array}{l}\text { Calcium and vitamin D for osteoporosis } \\
\text { IF a VE has osteoporosis, THEN he or she should be } \\
\text { prescribed calcium and vitamin D supplements. }\end{array}$ & 8.5 \\
\hline Osteoarthritis (OA) & $\begin{array}{l}\text { First-line pharmacological therapy } \\
\text { IF a VE is started on pharmacological therapy to treat OA, } \\
\text { THEN acetaminophen should be tried first. }\end{array}$ & 8.5 \\
\hline
\end{tabular}


Table 3. Independent risk factors associated to Inappropriate Prescribing (IP), Potentially Inappropriate Medicines (PIM) and Potentially Prescribing Omissions (PPO). Multivariate logistic regression analysis.

\begin{tabular}{|c|c|c|c|c|}
\hline Risk Factor & Global IP (n: 597) & No global IP (n: 75) & OR & $95 \% \mathrm{CI}$ \\
\hline $\begin{array}{cl}\text { Gender } & \\
\bullet & \text { Female } \\
\bullet & \text { Male }\end{array}$ & $\begin{array}{c}58.71 \\
41.3\end{array}$ & $\begin{array}{l}36.19 \\
63.81\end{array}$ & $\begin{array}{c}2.36 \\
1\end{array}$ & $1.31-4.25$ \\
\hline $\begin{array}{cl}\text { Number of medicines } \\
\text { - } 10 \text { or more } \\
\text { - } 5-9 \\
\text { - } \quad 0-4\end{array}$ & $\begin{array}{c}59.12 \\
36.43 \\
4.45\end{array}$ & $\begin{array}{l}32.86 \\
37.48 \\
29.66\end{array}$ & $\begin{array}{c}11.34 \\
6.00 \\
1\end{array}$ & $\begin{array}{l}4.96-25.94 \\
2.63-13.67\end{array}$ \\
\hline Risk Factor & Global PIM (n: 488) & No global PIM (184) & $\mathbf{O R}$ & $95 \% \mathrm{CI}$ \\
\hline $\begin{array}{cl}\text { Gender } & \\
\bullet & \text { Female } \\
\bullet & \text { Male }\end{array}$ & $\begin{array}{l}59.94 \\
40.06\end{array}$ & $\begin{array}{l}44.05 \\
55.95\end{array}$ & $\begin{array}{c}1.72 \\
1\end{array}$ & $1.12-2.63$ \\
\hline $\begin{array}{cl}\text { Number of medicines } \\
\text { - } 10 \text { or more } \\
\text { - } 5-9 \\
\text { - } \quad 0-4\end{array}$ & $\begin{array}{c}62.13 \\
35.47 \\
2.4\end{array}$ & $\begin{array}{l}37.38 \\
39.77 \\
22.85\end{array}$ & $\begin{array}{c}14.16 \\
7.36 \\
1\end{array}$ & $\begin{array}{l}6.44-31.12 \\
3.34-16.22\end{array}$ \\
\hline $\begin{array}{c}\text { Global PPO } \\
\bullet \quad \text { Yes } \\
\bullet \quad \text { No }\end{array}$ & $\begin{array}{l}72.66 \\
27.34\end{array}$ & $\begin{array}{l}51.14 \\
48.86\end{array}$ & $\begin{array}{c}2.26 \\
1\end{array}$ & $1.44-3.56$ \\
\hline $\begin{array}{l}\text { Barthel index basal } \\
\text { - Total dependence } \\
\text { - Severe dependence } \\
\text { - Moderate dependence } \\
\text { - Mild dependence } \\
\text { - Independence }\end{array}$ & $\begin{array}{c}12.98 \\
8.62 \\
19.36 \\
47.91 \\
11.12\end{array}$ & $\begin{array}{c}3.39 \\
11.11 \\
22.01 \\
46.20 \\
17.29\end{array}$ & $\begin{array}{c}5.42 \\
0.75 \\
0.84 \\
1.28 \\
1\end{array}$ & $\begin{array}{c}1.96-14.98 \\
0.30-1.83 \\
0.40-1.74 \\
0.67-2.46\end{array}$ \\
\hline Risk Factor & Global PPO (483) & No global PPO (189) & OR & $95 \% \mathrm{CI}$ \\
\hline $\begin{array}{c}\text { Multimorbidity }^{\mathrm{a}} \\
\text { - } \quad \text { Yes } \\
\text { - No }\end{array}$ & $\begin{array}{l}67.18 \\
32.82\end{array}$ & $\begin{array}{l}51.18 \\
48.82\end{array}$ & $\begin{array}{c}1,93 \\
1\end{array}$ & $1,25-2,97$ \\
\hline $\begin{array}{c}\text { Global PIM } \\
\qquad \quad \text { Yes } \\
\bullet \quad \text { No }\end{array}$ & $\begin{array}{l}80.79 \\
19.21\end{array}$ & $\begin{array}{l}62.34 \\
37.66\end{array}$ & $\begin{array}{c}2,79 \\
1\end{array}$ & $1,81-4,28$ \\
\hline $\begin{array}{c}\text { Barthel index basal } \\
\text { - Total dependence } \\
\text { - Severe dependence } \\
\text { - Moderate dependence } \\
\text { - Mild dependence } \\
\text { - Independence }\end{array}$ & $\begin{array}{c}8.98 \\
9.06 \\
22.65 \\
46.43 \\
12.88\end{array}$ & $\begin{array}{c}13.81 \\
9.64 \\
14.65 \\
49.63 \\
12.27\end{array}$ & $\begin{array}{c}0.29 \\
0.52 \\
0.95 \\
0.67 \\
1\end{array}$ & $\begin{array}{l}0.12-0.68 \\
0.21-1.24 \\
0.43-2.07 \\
0.35-1.28\end{array}$ \\
\hline $\begin{array}{l}\text { Dwelling } \\
\qquad \quad \text { Others } \\
\bullet \quad \text { Community }\end{array}$ & $\begin{array}{l}14.96 \\
85.04\end{array}$ & $\begin{array}{c}8.55 \\
91.45\end{array}$ & $\begin{array}{c}2.20 \\
1\end{array}$ & $1.14-4.25$ \\
\hline
\end{tabular}

Global IP was considered when a patient was prescribed with at least one Beer's, STOPP, START and/or ACOVE criteria.

Global PIM was considered when at least one Beers and/or STOPP criterion was prescribed, and global PPO, when at least one START and/or ACOVE-3 criteria was prescribed.

a ( $\geq 2$ clinical categories in the Polypathological Patient scale) [23] 
Table 4. Independent risk factors associated with Beers, STOPP, START and ACOVE3 criteria. Multivariate logistic regression analysis.

\begin{tabular}{|c|c|c|c|c|}
\hline Risk Factor & Beers (n: 317) & No Beers (n: 355) & OR & $95 \% \mathrm{CI}$ \\
\hline $\begin{array}{cl}\text { Gender } & \\
\bullet & \text { Female } \\
\bullet & \text { Male } \\
\end{array}$ & $\begin{array}{l}61.8 \\
38.2 \\
\end{array}$ & $\begin{array}{l}49.8 \\
50.2\end{array}$ & $\begin{array}{c}1.57 \\
1\end{array}$ & $1.07-2.3$ \\
\hline $\begin{array}{l}\text { Age } \\
75-84 \text { years } \\
85 \text { and over }\end{array}$ & $\begin{array}{l}68.28 \\
31.72\end{array}$ & $\begin{array}{l}59.35 \\
40.65\end{array}$ & $\begin{array}{c}1,53 \\
1\end{array}$ & $1.07-2.2$ \\
\hline $\begin{array}{c}\text { Number of medicines } \\
\begin{array}{cl}\text { - } & 10 \text { or more } \\
\text { - } & 5-9 \\
\text { - } & 0-4\end{array}\end{array}$ & $\begin{array}{c}66.42 \\
31.98 \\
1.6\end{array}$ & $\begin{array}{l}44.88 \\
41.34 \\
13.79\end{array}$ & $\begin{array}{c}8.19 \\
4.71 \\
1\end{array}$ & $\begin{array}{l}3.01-22.28 \\
1.71-12.99\end{array}$ \\
\hline Risk factor & STOPP (n: 414) & No STOPP (n: 258) & OR & $95 \% \mathrm{CI}$ \\
\hline $\begin{array}{cl}\text { Multimorbidity }^{\mathrm{a}} \\
\qquad \quad \text { Yes } \\
\text { - } \mathrm{No} \\
\end{array}$ & $\begin{array}{l}63.54 \\
36.46\end{array}$ & $\begin{array}{l}59.38 \\
40.62\end{array}$ & $\begin{array}{c}0.57 \\
1\end{array}$ & $0.36-0.92$ \\
\hline $\begin{array}{c}\text { Number of medicines } \\
\text { - } 10 \text { or more } \\
\text { - } 5-9 \\
\text { - } \quad 0-4\end{array}$ & $\begin{array}{c}64.17 \\
33.45 \\
2.38\end{array}$ & $\begin{array}{l}42.71 \\
41.49 \\
15.79\end{array}$ & $\begin{array}{c}8.21 \\
4.13 \\
1\end{array}$ & $\begin{array}{c}3.47-19.44 \\
1.74-9.78\end{array}$ \\
\hline $\begin{array}{c}\text { Barthel index basal } \\
\text { - Total dependence } \\
\text { - Severe dependence } \\
\text { - Moderate dependence } \\
\text { - Mild dependence } \\
\text { - Independence } \\
\end{array}$ & $\begin{array}{c}13.07 \\
8.22 \\
19.35 \\
49.06 \\
10.3\end{array}$ & $\begin{array}{c}6.58 \\
10.89 \\
21.1 \\
44.98 \\
16.45\end{array}$ & $\begin{array}{c}3.79 \\
1.1 \\
1.33 \\
1.68 \\
1\end{array}$ & $\begin{array}{c}1.5-9.54 \\
0.46-2.63 \\
0.62-2.84 \\
0.86-3.3\end{array}$ \\
\hline $\begin{array}{c}\text { ACOVE3 criteria } \\
\qquad \quad \text { yes } \\
-\quad \text { No }\end{array}$ & $\begin{array}{l}65.63 \\
34.37\end{array}$ & $\begin{array}{l}41.94 \\
58.06\end{array}$ & $\begin{array}{c}2.68 \\
1\end{array}$ & $1.77-4.06$ \\
\hline Risk Factor & START (n: 374) & No START (298) & OR & $95 \% \mathrm{CI}$ \\
\hline $\begin{array}{cc}\text { Multimorbidity } \\
-\quad \text { Yes } \\
-\quad \text { No } \\
\end{array}$ & $\begin{array}{l}70.53 \\
29.47\end{array}$ & $\begin{array}{l}52.88 \\
47.12\end{array}$ & $\begin{array}{c}1.76 \\
1\end{array}$ & $1.14-2.7$ \\
\hline $\begin{array}{cc}\text { Global } & \text { PIM } \\
\bullet & \text { Yes } \\
\bullet & \text { No }\end{array}$ & $\begin{array}{l}56.01 \\
43.99\end{array}$ & $\begin{array}{l}37.38 \\
62.62 \\
\end{array}$ & $\begin{array}{c}1.6 \\
1\end{array}$ & $1.02-2.51$ \\
\hline $\begin{array}{l}\text { Dwelling } \\
\text { - Others } \\
\text { - Community }\end{array}$ & $\begin{array}{l}16.77 \\
83.23\end{array}$ & $\begin{array}{c}8.75 \\
91.25 \\
\end{array}$ & $\begin{array}{c}1.82 \\
1 \\
\end{array}$ & $1.02-3.24$ \\
\hline Risk Factor & ACOVE3 (n: 418) & No ACOVE3 (n: 254) & OR & $95 \% \mathrm{CI}$ \\
\hline $\begin{array}{c}\text { STOPP criteria } \\
\bullet \quad \text { Yes } \\
\bullet \quad \text { No }\end{array}$ & $\begin{array}{l}71.29 \\
28.71 \\
\end{array}$ & $\begin{array}{l}48.44 \\
51.56 \\
\end{array}$ & $\begin{array}{c}2.3 \\
1 \\
\end{array}$ & $1.51-3.49$ \\
\hline
\end{tabular}

a ( $\geq 2$ clinical categories in the Polypathological Patient scale) [23] 
Figure 1. Distribution of patients into the groups of inappropriate prescribing (weighted percentages).

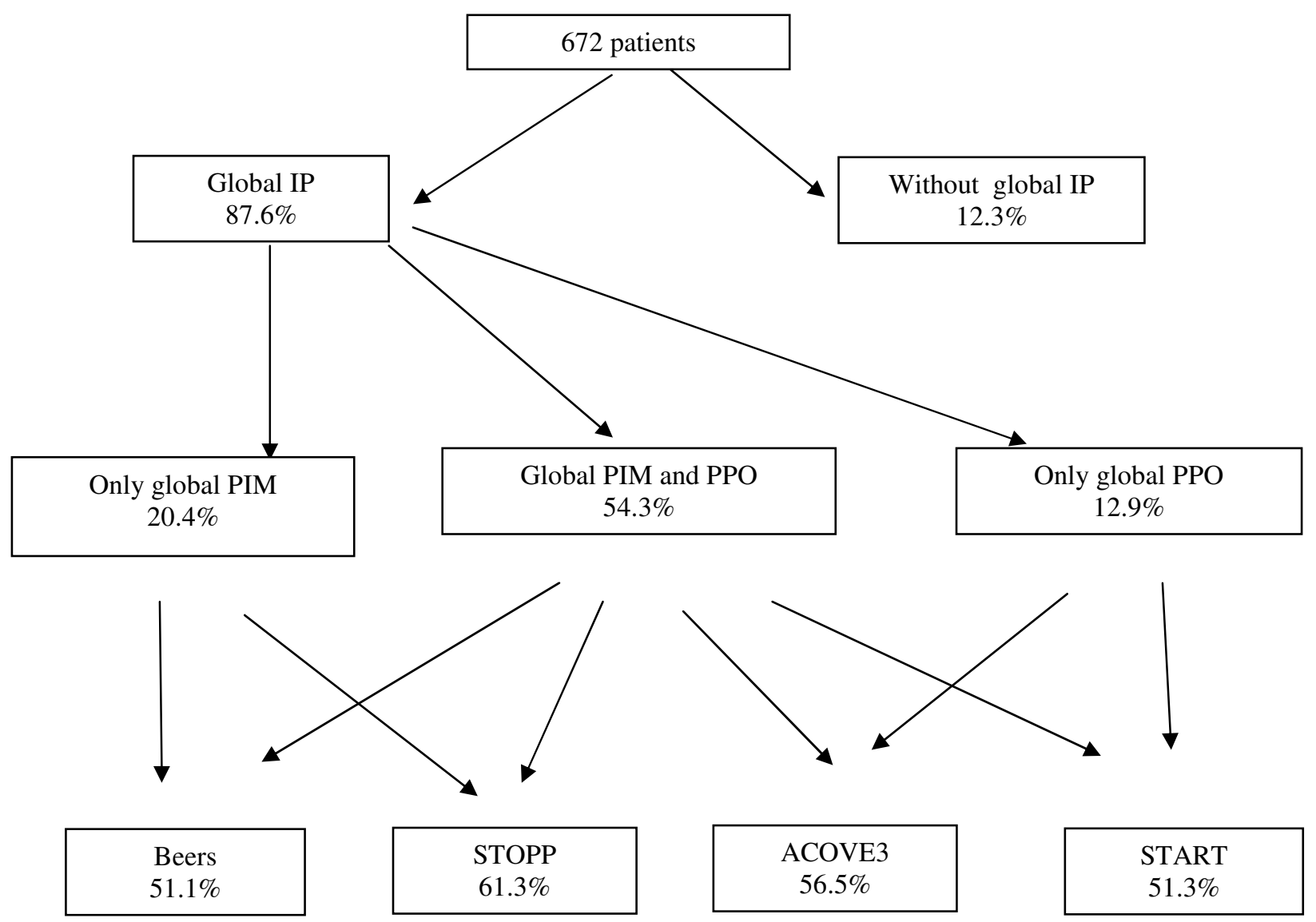

IP: Inappropriate Prescribing, PIM: Potentially Inappropriate Medicines; PPO: Potentially Prescribing Omissions

Global IP was considered when a patient was prescribed with at least one Beer's, STOPP, START and/or ACOVE criteria.

Global PIM was considered when at least one Beers and/or STOPP criterion was prescribed, and global PPO, when at least one START and/or ACOVE-3 criteria was prescribed. 